\title{
A CASE OF ACQUIRED DIAPHRAGMATIC HERNIA PRESENTING WITH PNEUMOTHORAX
}

\author{
Arudchelvam J D ${ }^{1}$, Dias $\mathrm{P}^{2}$, Weerasekara $\mathrm{D}^{3}$ \\ ${ }^{1}$ Registrar, Professorial Surgical Unit, Colombo South Teaching Hospital, Kalubowila, \\ ${ }^{2}$ Senior Registrar, Professorial Surgical Unit, Colombo South Teaching Hospital, Kalubowila, \\ ${ }^{3}$ Senior Lecturer, Department of Surgery, University of Sri Jayawardenepura, Nugegoda.
}

J D Arudchelvam MBBS

Registrar, Professorial Surgical Unit, Colombo South Teaching Hospital, Kalubowila.

P Dias MBBS, MS

Senior Registrar, Professorial Surgical Unit, Colombo South Teaching Hospital, Kalubowila.

D Weerasekara MBBS, MS, FRCS, FRCS(E)

Senior Lecturer, Department of Surgery, University of Sri Jayawardenepura, Nugegoda.

Corresponding author:

J D Arudchelvam, No. 53C, Waidya Road, Dehiwala.

Tel: 0775083151, 2722979.

\section{Introduction}

Diaphragmatic hernia can be congenital or acquired. Both are rare (1 in 2000 births). We report a case of acquired diaphragmatic hernia in a 23-year old male who presented with complications due to delayed diagnosis of traumatic diaphragmatic hernia.

\section{Case}

A 23-year old previously healthy male presented with colicky central abdominal pain for 2 weeks duration. He had constipation and abdominal distension. On examination there were exaggerated bowel sounds and reduced air entry in left lower chest. Supine abdominal X ray showed dilated caecum, ascending and transverse colon. Aloop of transverse colon appeared to enter left lower chest. A diaphragmatic hernia was suspected and on further questioning he gave a history of stab injury to left lower chest about 4 years back for which no interventions were done. While awaiting further investigations he developed sudden onset shortness of breath and increase in abdominal pain. An erect chest X ray showed left sided hydropneumothorax. An emergency midline thoracolaparotomy was performed. At surgery large bowel entering thorax through the anterior part of diaphragm about $1 \mathrm{~cm}$ posterior to anterior chest wall was noted with perforation and faecal matter inside thorax. Bowel loops were released and reduced into abdomen. Diaphragm and bowel perforation were repaired and a loop ileostomy was performed. Patient had an uneventful recovery except for left lower lobe pneumonia which responded to antibiotics.

\section{Discussion}

Blunt and penetrating trauma cause acquired diaphragmatic hernias. It occurs in approximately $3 \%$ of abdominal injuries with a 2:1 ratio of penetrating to blunt trauma $(1,2)$. The male-tofemale ratio is $4: 1$, with most presenting in the third decade of life (3).

These injuries remain undiagnosed in nearly half of the patients in the acute phase. Hence, delayed presentations are not uncommon. Indeed, they are often revealed by a complication (2). Delayed recognition of incarcerated diaphragmatic hernia after stab wounds to the lower left chest and upper abdomen has an associated mortality rate of $36 \%$ (4).

Patients can present with diffuse abdominal pain or respiratory distress and may have decreased breath sounds on the affected side, bowel sounds in chest and paradoxical breathing. Our patient presented with abdominal pain due to intestinal obstruction 
and later he developed respiratory distress due to intra thoracic perforation of bowel causing faecopneumothorax which is a rare presentation even though there are few reported cases $(2,5)$.

Chest radiography is more sensitive in detecting left sided diaphragmatic hernias. Features indicating diaphragmatic hernia include: abdominal contents within thorax with focal constriction (collar sign), nasogastric tube in thorax, more than $4 \mathrm{~cm}$ elevation of left hemi diaphragm and distortion of diaphragmatic margin. CT scan has a sensitivity of $14-82 \%$ and specificity of $87 \%$. Helical CT has $71-100 \%$ sensitivity which is higher for left side (1).

Diaphragmatic ruptures whether diagnosed immediately or delayed, should be repaired immediately because of associated morbidity and mortality of delayed treatment. Considering the morbidity associated with delayed presentation, exploratory laparotomy or laparoscopy is recommended for penetrating injury of lower chest especially on left side.

\section{References}

1. Vermillion JM, Wilson EB, Smith RW. Hernia 2001; 5(3): 158-60.

2. Jarry J, Razafindratsira T, Lepront D, Pallas G, Eggenspieler P, Dastes FD. Annales de Chirurgie 2006; 131(1): 48-50.

3. Sliker CW. Imaging of diaphragm injuries. Radiology Clinics of North America 2006; 44(2): 199-211.

4. Madden MR, Paull DE, Finkelstein JL, et al. Journal of Trauma 1989; 29(3): 292-8.

5. Kanowitz A, Marx JA. Journal of Emergency Medicine 1989; 7(6): 619-22. 